\title{
Análises físico-químicas de cerveja tipo IPA da Região Sul Fluminense
}

\author{
Physical and chemical analysis of ipa beer of the southern fluminese region
}

\section{Gabrielle Policarpo de Assis ${ }^{1 *}$, Beatriz Maria Baffa Lima², Lígia Marcondes Rodrigues dos Santos ${ }^{3}$}

Como citar esse artigo. de Assis, G.P.; Lima, B.M.B.; dos Santos, L.M.R. Análises físico-químicas de cerveja tipo IPA da Região Sul Fluminense. Revista Teccen. 2020 Jul./Dez.; 13 (2): 47-51.

\begin{abstract}
Resumo
O Brasil é um dos países de maior consumo de cerveja no mundo, entre elas a cerveja artesanal vem se destacando no aumento de produção e consumo, que devido aos diferentes processos de fabricação e uso de iguarias locais tem se destacado. O presente trabalho teve como objetivo a análise físico-química de três amostras de cerveja do tipo IPA (India Pale Ale) da região sul fluminense, onde foram analisadas extrato primitivo, extrato aparente, álcool, cor, espuma, amargor, célula de suspensão e pH, tendo como parâmetros de padrão do Ministério da Agricultura, Pecuária e Abastecimento (MAPA) e Beer Judge Certification Program (BJCP). Os resultados apresentados foram satisfatórios, porém análises como amargor e teor alcoólico tiveram resultados diferentes dos padrões e das informações apresentadas em seus rótulos..

Palavras-chave: Estilo de Cerveja, Padronização, Lúpulo, Alta Fermentação.
\end{abstract}

\begin{abstract}
Brazil is one of the countries with the highest consumption of beer in the world, among them craft beer has stood out in the increase of production and consumption, which due to the different processes of manufacture and use of local delicacies has stood out. The present work had as objective the physical-chemical analysis of three, of IPA type beer from the southern region of Rio de Janeiro, where primitive extract, apparent extract, alcohol, color, foam, bitterness, suspension cell and $\mathrm{pH}$ were analyzed, having as standard parameters of the Ministry of Agriculture, Livestock and Supply (MAPA) and Beer Judge Certification Program (BJCP). The results obtained were satisfactory, but analyzes such as bitterness and alcohol content had different results from the standards and information on their labels.

Keywords: Beer Style, Standardization, Hops, Top Fermentation.
\end{abstract}

\section{Introdução}

Mesmo sem exatidão, existem registros da existência da cerveja desde antes de Cristo (8000 a.C.), produzida pelos egípcios, sumérios e babilônicos (Souza e Andrade, 2017). Ela é uma bebida fermentada a base de cereais mais documentada desde período das navegações. Juntamente com pão e leite é um dos produtos mais consumidos mundialmente (Vargas, 2018). A bebida chegou ao Brasil através da família Real Portuguesa no ano 1808 e no ano de 2018 já existiam cerca de 889 cervejarias registradas no país segundo o Ministério de Agricultura e Pecuária (MAPA) (MAPA, 2019).
Segundo o Anuário da CervBrasil (2016), o setor cervejeiro foi responsável por $1,6 \%$ do PIB brasileiro, correspondendo a $14 \%$ das Indústrias de Transformação. Nele também é citado que o Brasil possui um dos maiores mercados consumidores de cerveja do mundo, o terceiro, perdendo apenas para China e EUA com um consumo de cerca de 15 milhões de litros por ano. Até o ano de 2019 foram registradas mais de 20 mil cervejas no Brasil, um crescimento médio de $19 \%$, em relação ao ano anterior (MAPA, 2019).

A cerveja artesanal tem sem seu processo características únicas, visto que é o mestre cervejeiro que cria sua receita tendo cores, aromas, sons e sabores diferenciados. Em seu processo de produção são

Afiliação dos autores:

${ }^{1}$ Discente do curso de Engenharia Química da Universidade de Vassouras, Vassouras, RJ, Brasil

${ }^{2}$ Docente do curso de Engenharia Química da Universidade de Vassouras, Vassouras, RJ, Brasil

* Email de correspondência: gabriellepa@outlook.com 
utilizados não apenas ingredientes básicos de fabricação (água, malte, lúpulo e levedura), com também iguarias como café, pimenta, banana, gengibre entre outros, que dão um toque diferenciado a cerveja. Desde a década de 80 , o Brasil fabrica cerveja artesanal e hoje está entre os maiores fabricantes do mundo (Lemos, 2016).

A produção de cervejas especiais em microcervejarias tem como público alvo pessoas de uma faixa etária de 26 a 39 anos e de classe média alta, devido ao seu paladar e valor diferenciado quando comparado as produzidas por grandes cervejarias (Almeida e Belo, 2017).

Ocrescimentodaproduçãoartesanal brasileiragera uma grande necessidade de controles físico-químicos de qualidade, onde os resultados encontrados nas análises devem estar dentro de um padrão estabelecidos pelo MAPA, órgão responsável formulação desses padrões de qualidade que a cerveja deve seguir (Almeida e Belo, 2017).

As cervejas apresentam uma enorme variedade de estilo e tipos, como as cervejas Lagers de baixa fermentação e as Ales, de alta fermentação, que são os tipos mais comuns. As cervejas do tipo Lager, são fermentadas por leveduras ativas em baixa temperatura entre $9^{\circ}$ e $15^{\circ}$ e as Ales por leveduras necessitam temperaturas altas entre $15^{\circ}$ a $25^{\circ}$. O consumo brasileiro é maior do tipo Lager sendo de $98 \%$, possui características como uma coloração mais clara, teor alcoólico baixo (cerveja tipo Pilsen). Devido ao clima tropical, este tipo se encaixa bem no perfil de consumo do brasileiro, por ser refrescante, leveza e baixo amargor (Almeida e Belo, 2017).

Segundo Junior (2018), o estilo IPA (India Pale Ale), é uma cerveja de teor alcoólico entre 5,5\% a 7,5\% (v/v), descoberta no final do século XVIII quando o povo britânico adicionou doses extras de lúpulo nas cervejas de alta fermentação (Ale) com a finalidade de preservála ao longo da viagem até a Índia. Quando chegaram lá puderam perceber um aroma e sabor de lúpulo mais acentuado. É uma cerveja mais encorpada, sua cor varia de dourado médio a leve âmbar-avermelhado, com um amargor característico, apresenta uma unidade de amargor (do inglês, Internacional Bitter Unit - IBU) entre 40 e 70. (BJCP, 2016)

A Instrução Normativa $N^{\circ} 65$ (IN 65), de 10 de Dezembro de 2019 regulamenta padrões de identificação e qualificação para produção de cervejas, e seus respectivos parâmetros analíticos (Brasil, 2019). Já o BJPC, estabelece padrões para produção de cervejas tipo IPA, pois a mesma caracteriza-se por uma lupulagem, amargura e paladar moderadamente fortes, com uma fermentação limpa. (BJCP, 2016)

Através da fermentação alcoólica do mosto oriundo da cevada e água potável, por meio de ação de levedura, com adição de lúpulo e eventualmente, adjuntos, é feita a fabricação da cerveja. Seus ingredientes básicos são água, malte de cevada e lúpulo, sendo o lúpulo o componente responsável por seu amargor e parte dos aromas. A sua adição ocorre durante a fervura do mosto, que é uma etapa que proporciona ao mosto e, por consequência à cerveja, a cor característica que varia do dourado ao acobreado. (Souza e Andrade, 2017). Segundo Figueirêdo (2017), a fermentação influencia também na coloração da cerveja, pois nesta etapa as leveduras absorvem parte das substâncias corantes presentes.

O presente trabalho teve como objetivo a análise físico-química de três amostras de cerveja do tipo IPA da região sul fluminense, onde foram analisados extrato primitivo, extrato aparente, álcool, cor, espuma, amargor, células em suspensão e $\mathrm{pH}$, tendo como parâmetros os padrões estabelecidos no BJCP e no MAPA.

\section{Materiais e Métodos}

O presente trabalho objetivou-se na realização de testes físico-químicos em 3 amostras de cerveja tipo IPA de marcas diferentes, comparando-as aos padrões estabelecidos pelo BJCP (2016), os padrões regulamentados pelo IN 65 (Brasil, 2019) e análises realizadas por cervejarias em grande escala. Essas análises foram: extrato primitivo, extrato aparente final, teor alcoólico, cor, espuma, pH e suspensão.

Através dos métodos European Brewery Convention (EBC), reconhecido pela IN 65 do MAPA (Brasil, 2019), foi realizada a análise de cor das amostras utilizando o espectrofotômetro do modelo DR4000 e leitura em um comprimento de onda de $430 \mathrm{~nm}$.

Para análise de amargor, realizada no mesmo espectrofotômetro, utilizou-se o iso-octano como solvente e posteriormente realizou-se a leitura no espectrofotômetro a $275 \mathrm{~nm}$. Segundo a BJCP (2016), uma cerveja IPA tem como padrão o amargor entre 40 e 70 IBU.

A análise de extrato foi realizada utilizando o equipamento Alcolyzer Beer ME - Modelo DMA 4500 M - Anton Paar. Os padrões estabelecidos pela Instrução Normativa $\mathrm{n}^{\circ}$ 65, de 10 de dezembro de 2019 (Brasil, 2019), determina que o extrato primitivo ou original de cervejas apresente valor igual ou superior a $5 \%(\mathrm{~m} / \mathrm{m})$. Para uma cerveja IPA, o padrão estabelecido pelo BJCP é entre 18,75 e $14 \%(\mathrm{~m} / \mathrm{m})(\mathrm{BJCP}, 2016)$.

Assim como a análise de extrato, a análise de álcool foi realizada no equipamento citado no parágrafo anterior. Para cervejas sem álcool o padrão estabelecido pelo IN 65 (Brasil, 2019), é de até $0,5 \%(\mathrm{v} / \mathrm{v})$, já para cervejas com álcool o padrão é de 0,5 a $54 \%$ (v/v). O BJCP (2016), indica que uma cerveja IPA deverá possuir uma concentração alcoólica entre 5 a 7,5\% (v/v).

O equipamento utilizado para análise de espuma foi o Niben, modelo TPH da empresa Haffmans, as 
análises de $\mathrm{pH}$ das amostras foram realizadas através de um pHmetro da marca Metrohm, modelo $827 \mathrm{pH}$ lab, e a análises de células em suspensão foram feitas utilizando o equipamento, Z2 Coulter Particle Count And Size Analyter da marca Beckman Coulter. Contudo, para tais análises não existem padrões estabelecidos pelo MAPA e pelo BJCP.

\section{Resultados e Discussões}

Os resultados das análises para todas as amostras foram apresentados na Tabela 1.

Tabela 1. Resultados das amostras analisadas

\begin{tabular}{lccc}
\hline ANÁLISE & Amostra I & Amostra 2 & Amostra 3 \\
\hline Extrato Primitivo ('P) & 13,15 & 11,87 & 16,04 \\
Extrato Aparente ( $\left.{ }^{\circ} \mathrm{P}\right)$ & 1,31 & 3,74 & 2,35 \\
Álcool (\% v/v) & 6,32 & 4,34 & 7,46 \\
Cor (EBC) & 31,02 & 22,07 & 24,00 \\
Espuma (s) & 278 & 312 & 205 \\
Amargor (IBU) & 48,16 & 60,30 & 81,00 \\
Célula em Suspensão & 3,86 & 5,18 & 2,27 \\
$\left(10^{6} / \mathrm{mL}\right)$ & 4,60 & 4,53 & 4,81 \\
$\mathrm{pH}$ & & & \\
\hline
\end{tabular}

\section{Extrato Primitivo ( $\left.{ }^{\circ} \mathrm{P}\right)$, Extrato Aparente $\left({ }^{\circ} \mathrm{P}\right)$, Álcool (\% v/v)}

Extrato primitivo é a quantificação das substâncias dissolvidas no mosto, isto é, a quantidade de ingrediente além de água que constituem a cerveja antes do início da fermentação (Oliveira e Plata-Oviedo, 2015). Todas as amostras apresentaram resultado acima de $5 \%(\mathrm{~m} / \mathrm{m})$.

No entanto, segundo o Guia de Estilos (BJCP), uma cerveja IPA deveria apresentar extrato primitivo entre 14,3 a $17,5^{\circ} \mathrm{P}$. No caso das amostras analisadas, somente a 3 se enquadraria neste parâmetro. Já em relação ao extrato aparente final, segundo o BJCP, ele deveria estar entre 2,5 e $4,0{ }^{\circ} \mathrm{P}$ para uma cerveja IPA característica. Somente a amostra 2 se enquadrou neste parâmetro.

Há também uma correlação com o extrato aparente, pois quanto maior a diferença entre o extrato primitivo e o aparente final, maior será o teor alcoólico. Esta diferença, expressa na forma de porcentagem, denomina-se Grau de Fermentação Aparente Final, calculado como a diferença entre o extrato primitivo e o aparente final, divido pelo extrato primitivo (Kunze, 2014).

Os resultados foram expressos na Tabela 2, e é possível observar que o teor alcoólico é sempre resultado do extrato consumido. Apesar da amostra 01 ter o maior grau de fermentação aparente percentual, quando se diminui o extrato original, do extrato final de cada amostra, é possível observar que a maior diferença de extratos corresponde ao maior teor alcoólico e assim sucessivamente, explicando o teor alcóolico de cada uma delas.

Uma cerveja é caracterizada alcoólica quando apresenta teor superior a $0,5 \%$, tal dado deverá ser apresentado em seu rótulo conforme a IN 65 (Brasil, 2019) e, neste estudo, todas as amostras adequaram-se ao padrão legal vigente no país.

Segundo o Guia de Estilos (BJCP) para cervejas do tipo IPA, este teor deve estar entre 5,5 e 7,5\%. Com isso, as amostras 1 e 3 apresentaram resultados dentro deste padrão estabelecido $(6,32$ e 7,46 \%, respectivamente). Porém a amostra 2 ficou abaixo do padrão $(4,34 \%)$, onde tal resultado foi influenciado pelo baixo grau de fermentação aparente como foi demostrado na Tabela 2.

Tabela 2. Diferença entre Extrato Primitivo e Original e teor alcoólico.

\begin{tabular}{lcc}
\hline & $\begin{array}{c}\text { Diferença entre Extrato Primitivo e } \\
\text { Original }(\%)\end{array}$ & Teor Alcoólico $\%$ (\%) \\
\hline Amostra 1 & 90 & 6,32 \\
Amostra 2 & 68 & 4,34 \\
Amostra 3 & 85 & 7,46 \\
\hline
\end{tabular}

Em relação à rotulagem, a IN 65 (Brasil 2019), exige que o teor alcoólico seja informado e sua tolerância em relação ao valor real seja de no máximo $0,5 \%(\mathrm{v} / \mathrm{v})$ para mais ou para menos. Desta forma, das amostras analisadas, tanto a 1 quando a 3 apresentaram valores dentro da tolerância, pois a amostra 1 apresentou $0,48 \%$ de diferença e a amostra $30,46 \%$. Já a amostra 2 apresentou em seu rótulo a informação de teor alcoólico de $6,5 \%$ e foi encontrado 4,34\% em análise, ou seja, uma diferença de $2,16 \%$ entre o valor informado e o Teal (teor alcoólico) e se encontra fora dos limites legais. Essa divergência pode ter sido ocasionada por alguma falha no controle de qualidade e no processo produtivo da cerveja. Outro motivo é o fato de que microcervejarias brasileiras, na grande maioria dos casos, não possuírem de equipamentos para tais análises, assim fazem cálculos matemáticos e esses valores são determinados por estimativa. Desta forma, o presente estudo corrobora o trabalho de Almeida e Belo (2017), que analisaram cervejas artesanais e industriais na cidade de Sete Lagoas - MG e obtiveram divergências similares.

\section{Cor (EBC)}

Até 2019, uma cerveja era considerada clara quando o valor obtido após análise era menor que 20 unidades EBC e escura quando o valor obtido é superior a 20 EBC, como estabelecido pelo IN 65 (Brasil, 2019). Contudo, não existe mais a classificação de cerveja clara e cerveja escura. O BJCP estabelece como padrão 
para cerveja IPA, valores entre 12 a 28 unidades EBC, onde as amostras 2 e 3 ficaram dentro desse padrão, já a amostra 1 ficou acima do valor estabelecido. Almeida e Belo (2017) descrevem tal divergência como possível erro durante processo de fabricação como maior tempo de fervura do mosto ou a utilização de um malte com cor mais escura. Cor não é uma análise rotineira em uma microcervejaria, o que reforça ainda mais a necessidade de controles analíticos de processo, ainda mais se a cor estiver indicada no rótulo da cerveja.

\section{Espuma (s)}

Espuma com estabilidade acima de 230 segundos é considerada uma boa espuma, segundo padrão de qualidade estabelecidos por grandes cervejarias. Cervejas do estilo IPAs possuem alto teor de iso- $\alpha$ ácidos (substâncias responsáveis pelo amargor do lúpulo), como a espuma é formada por iso- $\alpha$-ácidos em associação com o gás carbônico e proteínas de alto e médio peso molecular (Kunze, 2014).

As amostras 1 e 2 se adequaram ao padrão de qualidade estabelecido ( 278 e 312 s), porém a amostra 3 está abaixo do padrão apresentando $205 \mathrm{~s}$. Este valor diverge com o que é esperado, pois a amostra apresenta alto valor de IBU, sendo ele o maior dentre as 3 amostras. Possivelmente, houve um problema de baixa carbonatação na amostra, pois a espuma é formada pela tríade comentada acima.

\section{Amargor (IBU)}

O amargor da cerveja deve-se ao lúpulo, uma planta de característica sensoriais únicas que garante à cerveja aromas específicos além do amargor que é quantificado a partir dos $\alpha$-ácidos presentes. Para cervejas tipo IPA, o BJCP tem como padrão valores entre 40-70 IBUs. Mesmo não havendo uma legislação no Brasil que exija valores ou obrigatoriedade de ter informações de amargor em rótulos, é comum encontralos, uma vez que o amargor é um parâmetro importante para este estilo. Para as amostras analisadas neste estudo, somente a amostra 2 apresentou resultado de análise próximo ao informado no rótulo, enquanto que as outras amostras foram divergentes daqueles obtidos como demostra a Tabela 3.

As amostras 1 e 2 apresentaram resultados que se adequaram ao padrão estabelecido pelo BJCP, diferentemente da amostra 3 que apresentou resultado superior.

Como descrito por Souza e Andrade (2017), as divergências entre rótulo e análise dão-se ao fato que microcervejarias por motivos econômicos não realizam análises de amargor, com isso realizam cálculos matemáticos de aproximação estimando o percentual de utilização de $\alpha$-ácidos.

Tabela 3. Relação entre Amargor descrito no rótulo e obtido em análise.

\begin{tabular}{lcc}
\hline & $\begin{array}{c}\text { Amargor descrito no rótulo } \\
\text { (IBU) }\end{array}$ & $\begin{array}{c}\text { Amargor encontrado em } \\
\text { análise (IBU) }\end{array}$ \\
\hline Amostra 1 & 57 & 48,16 \\
Amostra 2 & 60 & 60,30 \\
Amostra 3 & 70 & 81,00 \\
\hline
\end{tabular}

\section{Célula em Suspensão}

Autólise do fermento é o que acontece quando a célula de levedura se rompe, liberando todo o conteúdo interno. Tal fenômeno é responsável pela liberação de matérias graxas e também pelo não consumo de todo açúcar disponível impactando negativamente nos aromas e na estabilidade da espuma. Além destes, a autólise também pode aumentar o $\mathrm{pH}$ final da cerveja e delegar aroma e paladar desagradáveis, a ponto do consumidor rejeitar o produto (Alegre, 2014).

A análise de células em suspensão indica a quantidade de células de levedura que permaneceram na cerveja, mesmo depois dos dias de maturação em baixas temperaturas. $O$ frio ajuda a decantação das células junto com o tempo, mas a cepa de levedura utilizada também influencia no poder de decantação (Figueirêdo, 2017).

A amostra 2 apresentou maior valor de células em suspensão (5,18 milhões $/ \mathrm{mL})$, já a amostra 3 foi a que apresentou o menor resultado (2,27 milhões $/ \mathrm{mL})$.

\section{pH}

Segundo Vargas (2018), o pH de uma cerveja deve estar 3,8 e 4,5. Isto se torna interessante, entre outras coisas, porque $\mathrm{m} \mathrm{pH}$ abaixo de 4,5 evita o crescimento de microrganismos patogênicos. Contudo, se o $\mathrm{pH}$ for abaixo de 3,8 , há um indicativo de presença de contaminantes deteriorantes como bactérias láticas e leveduras selvagens.

As amostras apresentaram altos valores de $\mathrm{pH}$, todas acima de 4,5, embora a amostra 2 estivesse bem próxima deste valor (4,53). Vargas (2018), cita que tais divergências de valores são influenciados pela água utilizada, o $\mathrm{pH}$ do mosto, o tipo de lúpulo e levedura utilizada no processo de fabricação, além da possibilidade de ter acontecido autólise nestas amostras, uma vez que todas possuíam células em suspensão.

\section{Considerações Finais}

A partir de análises físico-químicas realizadas em 3 cervejas artesanais do tipo IPA da região sul fluminense, foi realizado uma comparação entre esses dados e a IN 
65 (Brasil, 2019), junto ao Guia de Estilos (BJCP 2016) que possuem padrões pré estabelecidos para cervejas comercializadas e cervejas tipo IPA, respectivamente. Foram realizadas também análises que não possuem padrões definidos por estas duas instituições.

Os padrões estabelecidos pelo IN 65 (Brasil, 2019), são extrato primitivo, teor alcoólico e cor, no qual as amostras apresentaram resultados adequados aos estabelecidos pelo órgão.

As amostras quando comparadas ao BJCP (2016), que possui padrão de extrato primitivo, extrato aparente, amargor e teor alcoólico demostraram algumas discrepâncias, como:

- Para extrato primitivo 14,3 a $17,5^{\circ} \mathrm{P}$ e a amostra 3 foi a única a estar dentro deste padrão;

- Para extrato aparente final, as amostras deveriam apresentar resultado entre 2,5 e $4,0^{\circ} \mathrm{P}$, porém apenas a amostra 2 estava dentre deste intervalo;

- O amargor preconizado pelo BJCP deveria situar-se entre 40 e 70 IBUs, contudo amostra 3 apresentou resultado acima do pré estabelecido;

- Para teor alcoólico o Guia de Estilos estabelece para cervejas IPA um padrão entre 5,5 e 7,5\%, no qual a amostra 2 apresentou um teor alcoólico menor que o indicado.

Os valores relacionados ao teor alcoólico divergem, também, do indicado no rótulo, tal ocorrido pode estar relacionado a alguma falha de controle de qualidade, no processo de fabricação ou pelo fato de que microcervejarias não realizarem análises, mas sim estimativas deste valor, através de cálculos matemáticos.

Para parâmetros como espuma, $\mathrm{pH}$ e célula de suspensão a IN no 65 de 2019 e o $\operatorname{BJCP}$ (2015) não possuem padrões, porém existem condições para uma boa cerveja. Para uma boa espuma, ela deve estar acima de $230 \mathrm{~s}$, no qual as amostras 1 e 2 se adequaram a este padrão de qualidade. Para $\mathrm{pH}$, uma cerveja de qualidade deve estar 3,8 e 4,5 onde a amostra 3 apresentou um valor acima deste padrão. Os resultados obtidos a partir de análise de célula de suspensão indicaram maior quantidade na amostra 2.

De acordo com as análises realizadas no presente trabalho, pode-se concluir que as amostras de cerveja tipo IPA estão em sua maioria dentro dos padrões estabelecidos, apresentando resultados significativos e principalmente cervejas de boa qualidade para o consumidor.

\section{Referências}

Alegre, F., (2014). Determinação da qualidade de cerveja uma artesanal produzida em cuiabá-MT. Cuiabá.

Almeida, Denner Silva de, e Renata França Cassimiro Belo. (2017). “Análises
Físico-Químicas De Cervejas Artesanais E Industriais Comercializadas Em Sete Lagoas Mg”. Revista Brasileira De Ciências Da Vida 5(5): 1-16.

BJCP. (2016). “GUIA DE ESTILOS DE CERVEJAS”. Bjcp: 49

Brasil. (2019). "Diário oficial da união". : 1-7.

CervBrasil. (2016). "CervBrasil (Associação brasileira da indústria da cerveja)". : 63. http://www.cervbrasil.org.br/novo site/anuarios/CervBrasilAnuario2016_WEB.pdf.

Figueirêdo. (2017). "Universidade Estadual De Feira De Santana Programa De Pós-Graduação Em Biotecnologia Seleção De Leveduras E Produção De Cerveja Artesanal Suplementada Com Selênio". Trabalho de conclusão de curso. http://www2.uefs.br/ppgbiotec/portugues/arquivos/corpo discente/ doutorado/2013/antoniofrf-tese.pdf.

Gabriel, Pedro, Santos Souza, e Wesley Vertuan D E Andrade. (2017) "Caracterização do amargor da cerveja em microcervejarias da cidade de Ponta Grossa - PR." Trabalho de conclusão de curso.

Junior. (2018). "Produção de Cerveja Artesanal tipo IPA (India Pale Ale)". Trabalho de conclusão de curso.

Kunze, Wolfgang.Thecnology Brewing and Malting. Berlin: Vlb, p. 18-152, 2014.

Lemos. (2016). "Definição da melhor receita de Barbados Beer". Trabalho de conclusão de curso.

Mapa. (2019). “DECRETO No 9.902, DE 8 DE JULHO DE 2019”. : 2019.

Oliveira, Mariana, Carolina Rocha Faber, e Manuel Salvador Vicente PlataOviedo. (2015). "Craft Beer elaboration from partial replacement of malt by honey". Revista Brasileira de Pesquisa em Alimentos 6(3): 1.

Vargas, Beatriz de Oliveira. (2018). "DESENVOLVIMENTO, CARACTERIZAÇ̃̃O FÍSICO-QUÍMICA E AVALIAÇ̃̃O DO POTENCIAL ANTIOXIDANTE DE CERVEJAS TIPO ALE (IPA)". Trabalho de conclusão de curso. (September): 160-64. 